\title{
Determination of Iron in Vegetable Oil by Fourier Transform Mid-Infrared Spectroscopy
}

\author{
Pedro S. Panero ${ }^{1,4}$, Francisco S. Panero ${ }^{2,4}$, Jose C. S. Oliveira ${ }^{3}$, João S. Panero ${ }^{1,4}$, Anderson L. Ramos ${ }^{4}$, \\ Fernando S. E. D. V. Faria ${ }^{3,4}$ \& Anselmo F. R. Rodriguez ${ }^{3,4}$ \\ ${ }^{1}$ Federal Institute of Science and Technology of Roraima, Boa Vista, Brazil \\ ${ }^{2}$ Chemistry Department, Federal University of Roraima, Boa Vista, Brazil \\ ${ }^{3}$ Science and Technology Innovation Program, Federal University of Acre, Rio Branco, Brazil \\ ${ }^{4}$ Biodiversity and Biotechnology Network of the Legal Amazon, Biotechnology Department, Federal University \\ of Acre, Rio Branco, Brazil \\ Correspondence: Anselmo F. R. Rodriguez, Biodiversity and Biotechnology Network of the Legal Amazon, \\ Biotechnology Department, Federal University of Acre, Road BR 364, Km 04, CEP 69915-900, Rio Branco, \\ Brazil. Tel: 55-683-901-2719. E-mail: ruiz@ufac.br
}

Received: December 3, 2017

Accepted: January 4, $2018 \quad$ Online Published: February 15, 2018

doi:10.5539/jas.v10n3p81

URL: https://doi.org/10.5539/jas.v10n3p81

\begin{abstract}
The potential of Fourier transform mid-infrared spectroscopy with attenuated total reflection (FTIR-ATR) for the quantification of iron ( $\mathrm{Fe}$ ) in vegetable oil extracted from the fruit of the moriche palm (buriti) [Mauritia flexuosa] was evaluated. This green method enables direct measurements without previous sample handling. Twenty-five buriti samples were collected in Roraima (Brazil). The statistical models were developed using the technique of partial least squares (PLS) analysis and the data set was divided into two parts: one used for calibration $(\mathrm{n}=20)$ and one used for testing $(n=5)$. First, the model was calibrated and cross-validated with the calibration data set so that the model was validated with the test data set to verify its prediction ability. To obtain reference data, the samples were analyzed by X-ray fluorescence (EDXRF). The coefficient of determination $\left(\mathrm{R}^{2}\right)$ was 0.9965 and the mean square error of prediction (RMSEP) obtained for iron (Fe) was 0.8067 (in ppm). The results showed that the prediction ability can be considered good for large quantification of iron intervals in vegetable oil, and the mean relative errors were less than $\pm 7 \%$. This indicated that the green method for the determination of iron (Fe) in vegetable oil by Fourier transform mid-infrared spectroscopy with attenuated total reflection can be used as an alternative method to the classic methods of analysis, because it does not use reagents harmful to the environment or operator, does not generate harmful waste, uses a fast technique, and there is minimal manipulation of the sample.
\end{abstract}

Keywords: iron quantification, Mauritia flexuosa, mid-infrared, vegetable oil

\section{Introduction}

The Amazon region stands out for the enormous diversity of exotic fruits and has a great diversity of palm trees that occur in different ecosystems. Moriche palm (Mauritia flexuosa) is one of the most useful palm trees in the Amazon, being found in an extensive area, along the rivers, forests, and savannas, in several Brazilian states and South American countries (Ferreira, Lucien, Amaral, \& Silveira, 2008; Gilmore, Endress, \& Horn, 2013; Padoch, Ayres, Pinedo-Vasquez, \& Henderson, 1999). The fruit of the moriche palm, called buriti, is widely used by the local, riverside, and indigenous population due to the high nutritional value. It can be consumed fresh or as ingredients in juices, cakes, sweets and popsicles, as well as cooking oil for medical purposes by indigenous people (Ribeiro, 2010).

Some years ago, the buriti proved to be promising in research on compositions of bioactive compounds, such as sterols, tocopherols and carotenoids and presented application potentiality as a raw material for the extraction of oils for use in the food and cosmetic industries. Recent studies have shown that buriti oils can be considered beneficial for human health, because they present important phytochemical sources of unsaturated fatty acids, phytosterols, $\beta$-carotene, among others (Santos, Alves, \& Roca, 2015). 
Buriti oil is rich in monounsaturated fatty acids and a potential candidate for the prevention of cholesterol called LDL (low-density lipoprotein) (Albuquerque et al., 2005). It also has capacity in antiplatelet activity and inhibition of thrombosis formation and can be used in the prevention of cardiovascular diseases (Fuentes et al., 2013; Webb et al., 2008). Because of its emollient properties, it is used in the cosmetic industry as an adjunct to sun protection formulations (Zanatta, Mitjans, Urgatondo, Rocha-Filho, \& Vinardell, 2010). Recent research has shown that buriti oil is a good natural antioxidant, with potential for use in food systems, even at high temperatures (Forero-Doria et al., 2015). Being considered a good source of vitamin E, with a higher concentration than many kinds of cereal and legumes, being able to present high total levels of tocopherols (more than 100\%) compared to patauá, mari, tucumã, and inajá oils (Rodrigues, Darnet, \& Silva, 2010).

Iron is an essential nutrient for life and primarily acts on the synthesis of red blood cells and transport of oxygen to all cells of the body. However, according to National Iron Supplementation Program (2017), iron deficiency anemia is the largest nutritional deficiency in the world, affecting all social classes, especially children under two years of age and pregnant women. Iron deficiency anemia can have an adverse effect on psychomotor and mental development in children, and the mortality and morbidity of mother and infant during pregnancy (Gibney, Lanham-New, Cassidy, \& Vorster, 2009; Oski, 1979; Lozoff, Wolf, \& Jimenez, 1996; Almeida et al., 2004).

In view of the harm caused by insufficient iron intake, the labeling of iron content in foods is important, however, food products need to be inspected more quickly and efficiently.

In the literature, many conventional methods for scientific research are not green, because they produce harmful residues during and after analytical processes. The determination of the mineral elements in food is commonly done using atomic spectroscopy, however, the sample needs to be mineralized and then converted into solution. For this, methodologies involving the use of strong acids and other reagents are required, and, unfortunately, this process time-consuming, cost energy, and generating a lot of waste. On the other hand, nowadays scientists are aiming to development of methodologies that can reduce or eliminate reagent consumption and minimize working time through highly efficient analyzes (Namieśnik, 2001).

The mid-infrared spectroscopy (MIR), $4000-400 \mathrm{~cm}^{-1}$, is based on fundamental molecular vibrations and associated rotational vibration effects and is known to have more intense fundamental bands if compared whit near-infrared spectroscopy (Nunes, 2014). The infrared spectroscopy methods have been employed as an alternative to wet chemistry atomic spectroscopy procedures for food analysis (Mir-Marqués, Martínez-García, Garrigues, Cervera, \& de la Guardia, 2016), because they do not harm the environment and the products and, moreover, they strengthen the sustainable development that is useful for the society.

FTIR spectroscopy combined with chemometric techniques is proved to be a successful analytical method for the quantitative modeling of a wide variety of oils, foods, and plants (Sinelli et al., 2010). Also has already proved to be useful in the detection of pig lard in vegetable oils (Rohman, Man, Hashim, \& Ismail, 2011) when combined with the least squares regression (PLS) method. But the literature reports only a few papers that show the analysis of mineral elements in food matrices using MIR spectroscopy (Schmitt, Garrigues, \& de la Guardia, 2014) and none focusing on the buriti oil.

Moros, Iñón, Khanmohammadi, Garrigues and de la Guardia (2006) combined FTIR-ATR and PLS for the determination of calcium in commercial yogurt. Reeves (2001) has indicated that MIR spectroscopy has potential to measure phosphorus $(\mathrm{P})$ in dried poultry manures. The MIR spectroscopy application in dried dairy manure was also developed, and calibrations for fiber were possible, but calibrations for minerals were not successful (Reeves \& Kessel, 2002). Soyeurt et al. (2009) developed equations to measure $\mathrm{Ca}, \mathrm{K}, \mathrm{Mg}$, Na, and P contents directly in bovine milk using MIR spectrometry. The MIR use to estimate iron and zinc contents in powdered milk has also been described (Wu, He, Shi, \& Feng, 2009).

Therefore, considering the buriti oil as raw material of economic and social value, in order to demonstrate the possibility of use Fourier transform infrared spectroscopy with attenuated total reflection in direct measurements, without the previous treatment of the sample, as an alternative to the classical methods, the potential of (FTIR-ATR) combined with multivariate calibration (PLS) to the quantification of iron (Fe) in oils extracted from the pulps of buriti fruits was evaluated.

\section{Method}

\subsection{Sampling and Studied Area}

The state of Roraima is located in northern Brazil, in the region of the Western Amazon, it borders the states of Amazonas and Pará, as well as the nations of Venezuela (North and West) and Guyana (East and North), with 
latitude: $1^{\circ} 20^{\prime} 05.1^{\prime \prime} \mathrm{N}$ and longitude: $61^{\circ} 18^{\prime} 11.6^{\prime \prime} \mathrm{W}$. It is a region divided into 15 municipalities that covers a surface area of about $225000 \mathrm{~km}^{2}$.

A total of 25 samplings of fruit of the moriche palm were obtained from different regions of the state of Roraima: Mucajaí, Caroebe, Boa Vista, São João da Baliza, and Entre Rios, within a radius of 100 meters from the following locations (lat. $2^{\circ} 33^{\prime} 55.8^{\prime \prime} \mathrm{N}$ and long. 61 $31^{\prime} 06.8^{\prime \prime} \mathrm{W}$ ), (lat. $0^{\circ} 45^{\prime} 51.4^{\prime \prime} \mathrm{N}$ and long. 59 $23^{\prime} 51.8^{\prime \prime}$

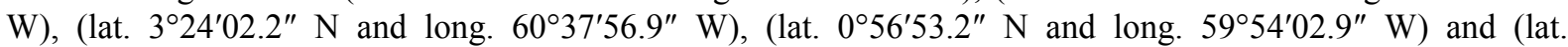
$0^{\circ} 51^{\prime} 27.6^{\prime \prime} \mathrm{N}$ and long. 59॰37'57.0" W).

\subsection{Sample Preparation}

Initially, the pulp of each sample was removed manually, subjected to grinding by a food processor, and was dried in the oven at a controlled temperature of $65^{\circ} \mathrm{C}$ for 24 hours. Subsequently, each sample was carefully packaged in filter paper, and was maintained in constant reflux and cycling in the Soxhlet extractor, for 5 hours with $250 \mathrm{~mL}$ of ethyl ether (Instituto Adolfo Lutz, 2008). On completion of the extraction, the ethyl ether was recovered and the samples, after being subjected to the rotary vacuum evaporation system, were stored in specific vials with the appropriate numbering.

\subsection{Acquisition of Spectral Data}

Fourier transform mid-infrared spectroscopy coupled with the attenuated total reflection (ATR) technique was used to collect the infrared spectra of Amazon buriti oil samples. The spectra were recorded using the Fourier transform spectrometer "Spectrum Two FT-IR" (PerkinElmer) coupled to the ATR accessory. A new background spectrum was recorded before each sample and the spectra were recorded in a mid-infrared region (4000-450 $\mathrm{cm}^{-1}$ ) using the nominal $4 \mathrm{~cm}^{-1}$ recording resolution. About 100 microliters of sample were used. 50 scans were collected for each spectrum. The ATR element was cleaned with ethyl alcohol and dried with soft tissue paper prior to the acquisition of the new spectra.

\subsection{EDXRF Procedure}

Analysis of the iron $(\mathrm{Fe})$ contents present in the buriti oil was performed by Shimadzu EDXRF-720 energy dispersive X-ray fluorescence spectrometry. The following equipment operating conditions were selected: tube voltage of $15 \mathrm{keV}$ ( $\mathrm{Na}$ to $\mathrm{Sc}$ ) and $50 \mathrm{keV}$ (Ti to $\mathrm{U}$ ) with current in the tube of 184 and $25 \mu \mathrm{A}$, respectively; $10 \mathrm{~mm}$ collimator; real integration time of $300 \mathrm{~s}$; detector dead time of 40 and 39\%, under vacuum and $\mathrm{Si}$ (Li) detector cooled with liquid nitrogen. One gram of the sample was packed in a polyethylene cup of $20 \mathrm{~mm}$ internal diameter and covered with $6 \mu \mathrm{m}$ thick polypropylene film (Mylar $\left.{ }^{\circledR}\right)$.

\subsection{Chemometrics Data Treatment}

Partial least squares regression (PLS) is probably the most widely used multivariate calibration method in chemometrics (Kowalski, 1984; Næs, Isaksson, Fearn, \& Davies, 2002). It is commonly used in quantitative spectroscopy to correlate spectroscopic data $(\mathrm{X})$ with related physical and chemical data (Y). In PLS, the decomposition of $\mathrm{X}$ during regression is guided by the variation in $\mathrm{Y}$ : the covariance explained between $\mathrm{X}$ and $\mathrm{Y}$ is maximized, so that the variation in $\mathrm{X}$ directly correlated with $\mathrm{Y}$ is extracted.

PLS is based on latent variables and, therefore, can handle highly collinear spectroscopic data in contrast to MLR (Massart, Vandeginste, Deming, Michotte, \& Kaufman, 1988). The linear model between the vector $Y_{c}$, containing the centered reference data, and the matrix $X_{c}$, containing the centered spectral data, can be described by:

$$
\mathrm{Y}_{\mathrm{c}}=\mathrm{X}_{\mathrm{c}} \mathrm{b}+\mathrm{e}
$$

where, $\mathrm{b}$ is a vector that contains the regression coefficients to be determined during the calibration, and e is the residue. In order to obtain a good estimation of $b$, the PLS model needs to be calibrated on samples that span the variation in $\mathrm{Y}$ well and in general are representative of the future samples.

Models for the estimation of iron contents in the Amazon buriti oil using its spectral measurements were performed with PLS regression. A definite PLS calibration model was constructed, using full cross-validation, employing the data of the selected samples and selected variables. Constructed model was used to predict the iron values for five samples (validation samples), using their spectral data (external validation). All data manipulation cited was done using The Unscrambler 9.2 software.

\section{Results and Discussion}

\subsection{MIR Spectra}

Figure 1 shows the raw FTIR-ATR spectrum $\left(4000-450 \mathrm{~cm}^{-1}\right)$ of buriti oil. Can be observed that all spectrum is dominated by some peaks, the vibration at $3005 \mathrm{~cm}^{-1}$ is assigned as $\mathrm{CH}$ stretching, related to $=\mathrm{C}-\mathrm{H}$ bonding. In the 
range between 2960 and $2840 \mathrm{~cm}^{-1}$, characteristic peaks of compounds with high triglycerides and fatty acids concentration, are assigned to $\mathrm{C}-\mathrm{H}$ stretching of methyl $\left(\mathrm{CH}_{3}\right)$ and methylene $\left(\mathrm{CH}_{2}\right)$ groups. The main peak at 1744 $\mathrm{cm}^{-1}$ arises from $\mathrm{C}=\mathrm{O}$ stretching vibrations, and this peak is associated with the triglyceride ester-linkage (COOR) band and the $\mathrm{C}=\mathrm{O}$ absorption with free fatty acid present in buriti oil.

It's important to highlight that although the literature does not point a specific absorption band in the infrared region for iron and other minerals, recent works, using whole spectral bands or symmetric division of the spectrum, have shown success for the quantification of these components in food using infrared spectroscopy combined with chemometric tools (Maarschalkerweerd \& Husted, 2015; Mir-Marqués et al., 2016; Schmitt et al., 2014).

Probably these indirect quantifications in the infrared region have been possible because mineral components can directly affect the shape and position of bands of other molecules due to their interactions (electrostatic and/or chelates) with certain functional groups, such as organic compounds, organic salts, hydrates and others (González-Martín, Hernandez-Hierro, Revilla, Vivar-Quintana, \& Ortega, 2011; Sauvage, Frank, Stearne, \& Millikan, 2002; Mir-Marqués et al., 2016; Schmitt et al., 2014).

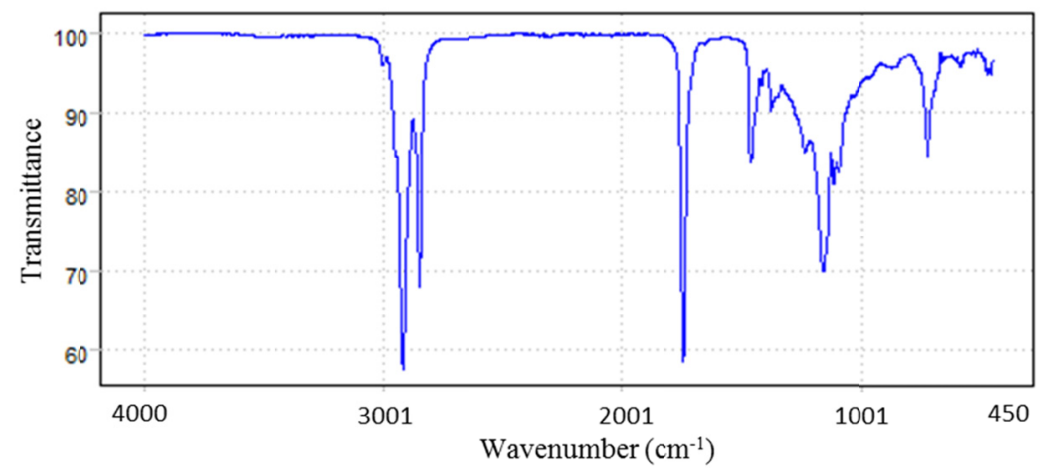

Figure 1. FTIR spectrum (4000-450 $\mathrm{cm}^{-1}$ ) of Amazon buriti (Mauritia flexuosa) oil

\subsection{PLS Models and Validation}

To minimize the effects caused by the difficulty of obtaining an ideal spectrum, or spectra without undesirable random or systematic variations of different origins, mathematical pre-treatments in the spectral data were performed: standard normal variate (SNV), multiplicative scatter correction (MSC), and extended multiplicative scatter correction (EMSC) to reduce and/or remove multiplicative interference or scatter effects, that are physical phenomena caused by particle size; smoothing processes were performed by a moving average; the first and second derivative of Savitzky-Golay were applied, because it has the ability to remove additive and multiplicative effects on the spectra, the first derivative removes only the baseline; the second derivative removes both the baseline and linear trend.

The number of latent variables (LVs) used to construct the PLS model was determined by full cross-validation. The ideal number of LVs is given by the minimum of the root mean square error of cross-validation (RMSECV) value. The PLS model was evaluated by the average accuracy (RMSECV) and root mean square error of prediction (RMSEP), coefficients of determination for the calibration set $\left(\mathrm{Rc}^{2}\right)$ and prediction set $\left(\mathrm{Rp}^{2}\right)$.

The complete set of spectral data was divided into two independent sets, calibration and validation, with 20 and 5 samples, respectively. For the regression models using PLS method, the number of LVs was defined through cross-validation using the calibration samples set. For the selection of the optimum number of LV, several parameters, such as the predicted residual error sum of squares (PRESS), root mean square error of cross-validation (RMSECV), and X and Y explained variances were evaluated.

The model that presented the lowest PRESS of validation was constructed with four latent variables, as indicated in the graph shown in Figure 2.

It is observed that the PRESS of internal validation decreases with the increase of the complexity of the model, that is, with the increase in the number of LVs used. This behavior was also observed in relation to the models constructed using a number of LVs of less than 3 and greater than 5, indicating that 4 is the optimal number of LVs to be considered in the models. 


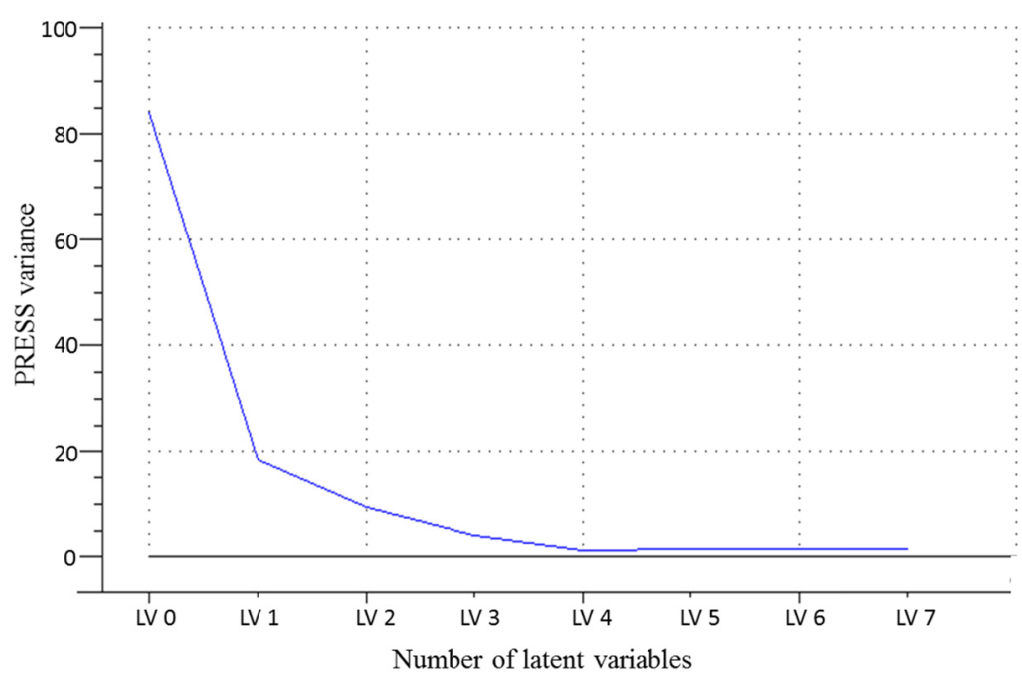

Figure 2. PRESS vs number of latent variables on the PLS calibration model

Table 1. FTIR-ATR modeling results of the estimative of iron obtained by different pre-treatment methods

\begin{tabular}{llllll}
\hline \multirow{2}{*}{ Spectral data } & \multicolumn{2}{c}{ Calibration sets } & & \multicolumn{2}{c}{ Prediction sets } \\
\cline { 2 - 3 } \cline { 5 - 6 } & $\mathrm{Rc}^{2}$ & RMSEC & & $\mathrm{Rp}^{2}$ & RMSEP \\
\hline Raw & 0.9974 & 0.6280 & & 0.9958 & 0.8084 \\
SNV & 0.9966 & 0.7227 & & 0.9921 & 0.8723 \\
MSC & 0.9965 & 0.7238 & & 0.9924 & 0.8812 \\
EMSC & 0.9966 & 0.7217 & & 0.9926 & 0.8765 \\
1st derivate & 0.9940 & 1.2677 & & 0.9892 & 1.4365 \\
2nd derivate & 0.9952 & 1.4321 & & 0.9903 & 1.6517 \\
MV=5 & 0.9974 & 0.6277 & & 0.9954 & 0.8176 \\
MV=10 & 0.9974 & 0.6274 & & 0.9965 & 0.8067 \\
\hline
\end{tabular}

Note. $\overline{\mathrm{RMSECV}}$ = root mean square error of cross-validation; RMSEP = root mean square error of prediction; $\mathrm{Rc}^{2}=$ coefficients of determination for the calibration set; $\mathrm{Rp}^{2}=$ coefficients of determination for the prediction set; $\mathrm{SNV}=$ standard normal variate; $\mathrm{MSC}=$ multiplicative scatter correction, $\mathrm{EMSC}=$ extended multiplicative scatter correction; $\mathrm{MV}=$ moving average.

Table 1 shows the PLS modeling results of the pre-processed ATR full-spectrum of estimative of iron for 4 LVs. Compared with the original data, the determination coefficients $\left(\mathrm{R}^{2}\right)$ of the MSC, EMSC, and SNV-processed spectrum models decreases and the root mean square error increased. After applied smoothing processes by a moving average with 5 and 10 windows, the RMSEC is decreased and $\mathrm{R}^{2}$ increased.

The absorbance data of all the training sets were obtained at $4000-450 \mathrm{~cm}^{-1}$. The correlation data of PLS model, in Figure 3, shows the good performance of the PLS model, indicated by the coefficient of determination $\left(R^{2}\right)$ higher than 0.99 and by the low RMSEC value.

Figure 3 shows the good correlation between the values of the iron content of the sample set and the experimental values EDXRF verified for the 20 samples used in the FTIR-ATR calibration set. Despite the low number of samples, the calibration curve was robust, since the collection covered a large territorial area with different phytoecologies, and considered a wide variability of iron concentration in the samples. Therefore, a set of representative and non-biased samples. 


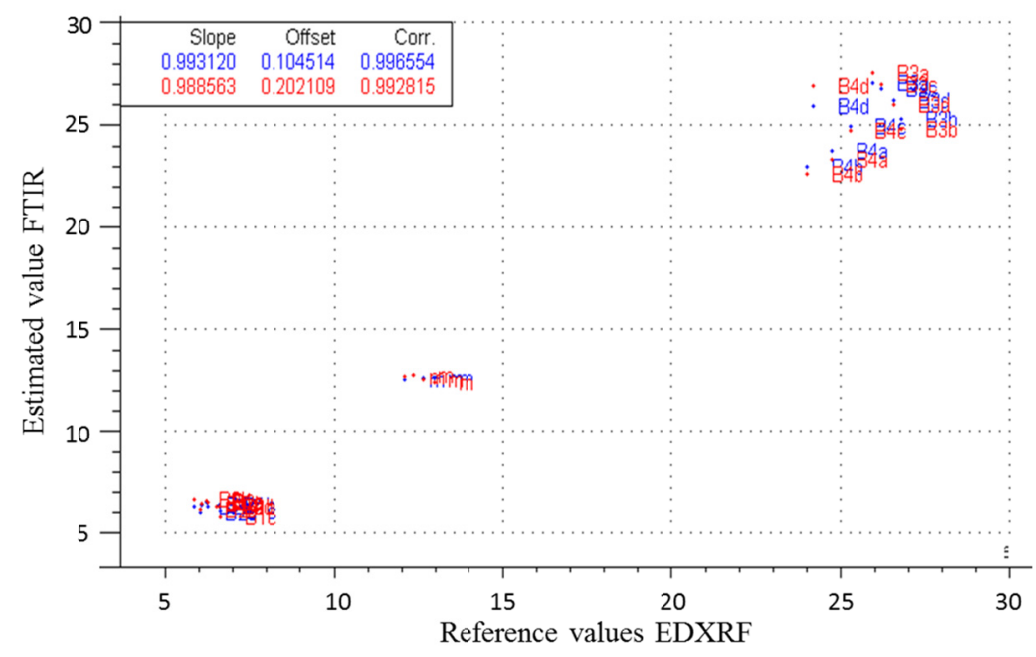

Figure 3. Scatter plot showing the correlation between the measured reference (in ppm) and predicted FTIR-ATR in the calibration set using PLS model

The low dispersion of the forecast values around the curve reveals a good predictive ability of the model. Through the same graph, it is possible to verify the high correlation between the values predicted by the proposed model and its reference values (accuracy), evidencing the absence of systematic errors in the results.

It is observed that the entire spectrum presents better results without pre-processing with a slight improvement after applying a moving average to 10 windows. The model developed through the calibration samples used was validated by external validation ( 5 samples).

Table 2 shows, for comparative purposes, the experimental values and the predicted values by FTIR-ATR in ppm. We can say that the oil of buriti is a good source of iron, since the values ranged from $6.5-26.0 \mathrm{mg} / \mathrm{kg}$, and second Azevedo and Chasin (2003), and Gibney et al. (2009), the daily intake of iron recommended for children is (7-10 $\mathrm{mg}$ ), teenage boys $(8-11 \mathrm{mg}$ ), adult men $8 \mathrm{mg}$, teenage girls $8-15 \mathrm{mg}$, adult women $8-18 \mathrm{mg}$ and pregnant women $27 \mathrm{mg}$, and can be supplied with a balanced diet. The mean relative errors between the chemometric method and the reference method were less than $\pm 7 \%$, the smallest error was $1.95 \%$ and the biggest error was $6.57 \%$, indicating a good predictability of the iron content by the proposed method for buriti oil samples.

The good result presented in this paper supports the possibility that the technique employed has potential to be used as a routine method in food quality laboratories, because can replace the traditional minerals analysis techniques that are time-consuming, degrade samples, and generate laboratory residues.

Therefore, we encourage unpublished studies aimed at the extraction and determination of iron-containing metalloproteins in buriti oil to investigate the percentage of iron present in each protein, in order to study the spectral absorption band of the metalloprotein responsible for the highest concentration of iron, since this could allow the development of calibration and prediction models using smaller (specific) spectral bands, capable of optimizing the evolution of new equipment dedicated to the determination of iron in vegetable oil.

Table 2. Comparative of experimental values and expected mean values (in ppm)

\begin{tabular}{llllll}
\hline Sample & 1 & 2 & 3 & 4 & 5 \\
\hline Predicted 1 & 6.581 & 12.714 & 26.054 & 25.003 & 6.601 \\
Reference(SD) & $6.175(0.385)$ & $12.471(0.580)$ & $24.780(0.967)$ & $25.878(1.195)$ & $6.374(0.392)$ \\
\hline
\end{tabular}

\section{Conclusion}

This study investigated the potential of Fourier transforms mid-infrared spectroscopy coupled with attenuated total reflection, combined with PLS chemometric technique to predict the iron content in buriti oil as an alternative method to the classic methods of analysis. The predicted models have enabled good results in the estimation of iron contents in buriti oil, fruit of the moriche palm (Mauritia flexuosa) from the Amazon region, 
with mean relative errors less than $\pm 7 \%$. The methodology used showed in agreement to the concepts of the green method because it did not use reagents that are harmful to the environment or operator and it enabled fast and efficient analysis with minimal manipulation of the sample.

\section{References}

Albuquerque, M. L., Guedes, I., Alcantara Jr., P., Moreira, S. G., Barbosa Neto, N. M., Correa, D. S., \& Zilio, S. C. (2005). Characterization of buriti (Mauritia flexuosa L.) oil by absorption and emission spectroscopies. Journal of the Brazilian Chemical Society, 16(6), 1113-1117. https://doi.org/10.1590/S0103-50532005000 700004

Almeida, C. A. N., Ricco, R. G., Del Ciampo, L. A., Souza, A. M., Pinho, A. P., \& Oliveira, J. E. D. (2004). Fatores associados a anemia por deficiência de ferro em crianças pré-escolares brasileiras. Jornal de Pediatria, 80(3), 229-234. https://doi.org/10.2223/1188

Azevedo, F. A., \& Chasin, A. A. M. (2003). Metais e gerenciamento da toxidade (1st ed.). São Paulo, SP: Atheneu.

Ferreira, E., Lucien, V., Amaral, A. S., \& Silveira, C. S. (2008). Caracterização físico-química do fruto e do óleo extraído de tucumã (Astrocaryum vulgare Mart). Alimentos e Nutrição Araraquara, 19(4), 427-433. Retrieved from http://serv-bib.fcfar.unesp.br/seer/index.php/alimentos/article/viewFile/652/548

Forero-Doria, O., Gallego, J., Valdes, O., Pinzon-Topal, C., Santos, L. S., \& Guzmán, L. (2015). Relationship between oxidative stability and antioxidant activity of oil extracted from the peel of Mauritia flexuosa fruits. Journal of Thermal Analysis and Calorimetry, 123(3), 2173-2178. https://oi.org/10.1007/s10973015-4822-7

Fuentes, E., Rodriguez-Pérez, W., Guzman, L., Alarcón, M., Navarrete, S., Forero-Doria, O., \& Palomo, I. (2013). Mauritia flexuosa presents in vitro and in vivo antiplatelet and antithrombotic activities. Journal Evidence-Based Complementary and Alternative Medicine, 2013, Article ID 653257. https://doi.org/ $10.1155 / 2013 / 653257$

Gibney, M. J., Lanham-New, S. A., Cassidy, A., \& Vorster, H. H. (2009). Introduction to Human Nutrition (2nd ed.). Chichester, UK: John Wiley \& Sons.

Gilmore, M. P., Endress, B. A., \& Horn, C. M. (2013). The socio-cultural importance of Mauritia flexuosa palm swamps (aguajales) and implications for multi-use management in two Maijuna communities of the Peruvian Amazon. Journal of Ethnobiology and Ethnomedicine, 9, 1-23. https://doi.org/10.1186/1746-4269-9-29

González-Martín, I., Hernandez-Hierro, J. M., Revilla, I., Vivar-Quintana, A. M., \& Ortega, I. L. (2011). The mineral composition ( $\mathrm{Ca}, \mathrm{P}, \mathrm{Mg}, \mathrm{K}, \mathrm{Na}$ ) in cheeses (cow's, ewe's and goat's) with different ripening times using near infrared spectroscopy with a fibre-optic probe. Food Chemistry, 127(1), 147-152. https://doi.org/10.1016/j.foodchem.2010.12.114

Instituto Adolfo Lutz. (2008). Métodos físico-químicos para análise de alimentos. São Paulo, SP: Instituto Adolfo Lutz.

Kowalski, B. R. (1984). Chemometrics: Mathematics and Statistics in Chemistry. Springer, Dordrecht. https://doi.org/10.1007/ 978-94-017-1026-8

Lozoff, B., Wolf, A. W., \& Jimenez, E. (1996). Iron-deficiency anemia and infant development: Effects of extended oral iron therapy. The Journal of Pediatrics, 129(3), 382-389. https://doi.org/10.1016/S00223476(96)70070-7

Maarschalkerweerd, M. V., \& Husted, S. (2015). Recent developments in fast spectroscopy for plant mineral analysis. Frontiers in Plant Science, 169(6), 1-14. https://doi.org/10.3389/fpls.2015.00169

Massart, D. L., Vandeginste, B. G., Deming, S. N., Michotte, Y., \& Kaufman, L. (1988). Chemometrics: A Textbook (1st ed.). Amsterdam, The Netherlands: Elsevier.

Mir-Marqués, A., Martínez-García, M., Garrigues, S., Cervera, M. L., \& de la Guardia, M. (2016). Green direct determination of mineral elements in artichokes by infrared spectroscopy and X-ray fluorescence. Food Chemistry, 196, 1023-1030. https://doi.org/10.1016/j.foodchem.2015.10.048

Moros, J., Iñón, F. A., Khanmohammadi, M., Garrigues, S., \& de la Guardia, M. (2006). Evaluation of the application of attenuated total reflectance-Fourier transform infrared spectrometry (ATR-FTIR) and chemometrics to the determination of nutritional parameters of yogurt samples. Analytical and Bioanalytical Chemistry, 385(4), 708-715. https://doi.org/10.1007/s00216-006-0418-1 
Næs, T., Isaksson, T., Fearn, T., \& Davies, T. (2002). A User-Friendly Guide to Multivariate Calibration and Classification. Chichester, UK: NIR Publications.

Namieśnik, J. (2001). Green analytical chemistry-Some remarks. Journal of Separation Science, 24, $151-153$. https://doi.org/10.1002/1615-9314(20010201)24:2<151::AID-JSSC151>3.0.CO;2-4

National Iron Supplementation Program. (2017). In Coordenação Geral da Política de Alimentação e Nutrição. Retrieved August 25, 2017 from http://nutricao.saude.gov.br/mn/ferro/ferro_programa_info_geral.php

Nunes, C. A. (2014). Review: vibrational spectroscopy and chemometrics to assess authenticity, adulteration and intrinsic quality parameters of edible oils and fats. Food Research International, 60, $255-261$. https://doi.org/10.1016/j.foodres.2013.08.041

Oski, F. A. (1979). The nonhematologic manifestations of iron deficiency. American Journal of Diseases of Children, 133(3), 315-322. https://doi.org/10.1001/archpedi.1979.02130030091017

Padoch, C., Ayres, J. M., Pinedo-Vasquez, M., \& Henderson, A. (1999). Várzea: diversity, development, and conservation of Amazonia's whitewater floodplains. New York, NY: The New York Botanical Garden Press.

Reeves, J. B. (2001). Near-versus mid-infrared diffuse reflectance spectroscopy for determination of minerals in dried poultry manure. Poultry Science, 80(10), 1437-1443. https://doi.org/10.1093/ps/80.10.1437

Reeves, J. B., \& Kessel, J. S. (2002). Near-versus mid-infrared diffuse reflectance spectroscopy for the analysis of dried dairy manures. Journal of Near Infrared Spectroscopy, 10, 93-101. https://doi.org/10.1255/jnirs.326

Ribeiro, G. H. (2010). Desenvolvimento de modelos alométricos para estimar biomassa e carbono de mudas de espécies arbóreas, em áreas atingidas por tempestade de vento em Manaus (Master's thesis, National Research Institute of the Amazon, Manaus, Brazil). Retrieved from http://bdtd.inpa.gov.br/bitstream/tede /1095/1/Dissertacao_Gabriel_Ribeiro.pdf

Rodrigues, A. M., Darnet, S., \& Silva, L. H. (2010). Fatty acid profiles and tocopherol contents of buriti (Mauritia flexuosa), patawa (Oenocarpus bataua), tucuma (Astrocaryum vulgare), mari (Poraqueiba paraensis) and inaja (Maximiliana maripa) fruits. Journal of the Brazilian Chemical Society, 21(10), 2000-2004. https://doi.org/10.1590/S0103-50532010001000028

Rohman, A., Man, Y. B. C., Hashim, P., \& Ismail, A. (2011). FTIR spectroscopy combined with chemometrics for analysis of lard adulteration in some vegetable oils. CyTA-Journal Food, 9(2), 96-101. https://doi.org/ $10.1080 / 19476331003774639$

Santos, M. F., Alves, R. E., \& Roca, M. (2015). Carotenoid composition in oils obtained from Amazonian palms fruits. Grasas y Aceites, 66(3), 86-93. https://doi.org/10.3989/gya.1062142

Sauvage, L., Frank, D., Stearne, J., \& Millikan, M. B. (2002). Trace metal studies of selected white wines: An alternative approach. Analytica Chimica Acta, 458(1), 223-230. https://doi.org/10.1016/S0003-2670 (01)01607-5

Schmitt, S., Garrigues, S., \& de la Guardia, M. (2014). Determination of the mineral composition of foods by infrared spectroscopy: A review of a green alternative. Journal Critical Reviews in Analytical Chemistry, 44(2), 186-197. https://doi.org/10.1080/10408347.2013.835695

Sinelli, N., Casale, M., Egidio, V., Oliveri, P., Bassi, D., Tura, D., \& Casiraghi, E. (2010). Varietal discrimination of extra virgin olive oils by near and mid infrared spectroscopy. Food Research International, 43(8), 2126-2131. https://doi.org/10.1016/j.foodres.2010.07.019

Soyeurt, H., Bruwier, D., Romnee, J. M., Gengler, N., Bertozzi, C., Veselko, D., \& Dardenne, P. (2009). Potential estimation of major mineral contents in cow milk using mid-infrared spectrometry. Journal of Dairy Science, 92(6), 2444-2454. https://doi.org/10.3168/jds.2008-1734

Webb, A. J., Patel, N., Loukogeorgakis, S., Okorie, M., Aboud, Z., Misra, S., ... Ahluwalia, A. (2008). Acute blood pressure lowering, vasoprotective, and antiplatelet properties of dietary nitrate via bioconversion to nitrite. Hypertension, 51(3), 784-790. https://doi.org/10.1161/hypertensionaha.107.103523

Wu, D., He, Y., Shi, J., \& Feng, S. (2009). Exploring near and mid-infrared spectroscopy to predict trace iron and zinc contents in powdered milk. Journal of Agricultural and Food Chemistry, 57(5), 1697-1704. https://doi.org/10.1021/jf8030343 
Zanatta, C. F., Mitjans, M., Urgatondo, V., Rocha-Filho, P. A., \& Vinardell, M. P. (2010). Photoprotective potential of emulsions formulated with Buriti oil (Mauritia flexuosa) against UV irradiation on keratinocytes and fibroblasts cell lines. Food and Chemical Toxicology, 48(1), 70-75. https://doi.org/10.1016/j.fct.2009. 09.017

\section{Copyrights}

Copyright for this article is retained by the author(s), with first publication rights granted to the journal.

This is an open-access article distributed under the terms and conditions of the Creative Commons Attribution license (http://creativecommons.org/licenses/by/4.0/). 